\title{
El legado del impresor zaragozano Miguel Montañés
} (1727-1731)

\author{
Alejandrina Aguas COMPAIRED y Ana BALLeStero PASCUAL \\ (Universidad de Zaragoza)
}

\section{Resumen}

Miguel Montañés fue un impresor nacido en Lécera, municipio ubicado a tan solo 60 kilómetros de Zaragoza, aunque toda su carrera se desarrolló en la capital aragonesa. A través de su testamento se ha conseguido establecer dos hechos fundamentales para la imprenta dieciochesca zaragozana. Por una parte, se ha esclarecido el origen de la imprenta de Miguel Montañés y por otra, la continuación del taller en manos de sus dos herederos, Diego Guindeo y Juan Malo.

Palabras clave: Miguel Montañés; Zaragoza; imprenta; s. XVIII; Diego Guindeo; Juan Malo; Pascual Bueno; Hospital de Nuestra Señora de Gracia.

\section{The legacy of the printer Miguel Montañés}

$$
\text { (1727-1731) }
$$

\section{Abstract}

The printer Miguel Montañés was born in Lécera but spent his entire career in Zaragoza, some 60 miles away. A study of his will allows us to establish two fundamental facts about printing there in the 18th century: first, we now have a clearer idea about the origin of his press and, second, we know that it was taken over by his two heirs Diego Guindeo and Juan Malo.

Keywords: Miguel Montañés; Saragossa; Printing; 18th century; Diego Guindeo; Juan Malo; Pascual Bueno; The Hospital of Nuestra Señora de Gracia (Saragossa). 


\section{Contexto cultural}

En el siglo XVIII Zaragoza ya era un centro editorial de renombre al contar con instituciones capaces de sustentar la industria libraría. En la capital aragonesa se estaba generando una economía floreciente gracias a una universidad que crecía constantemente y a corporaciones religiosas y administrativas de cierto renombre que apoyaban el mundo intelectual. En estas fechas la ciudad poseía 29.601 habitantes $^{1}$ de los cuales cuarenta pertenecían a este sector, siete eran impresores y otros tantos libreros, mientras que el resto de estos trabajadores se distribuían en oficios varios.

En este contexto profesional y cultural trabajó Miguel Montañés, uno de los impresores encargados del taller tipográfico que realizó encargos para el Hospital de Nuestra Señora de Gracia, del que no se conoce apenas datos profesionales. Algunos documentos encontrados recientemente, que se dan a conocer en este trabajo, han podido esclarecer parte de su trayectoria laboral y al mismo tiempo, descubrir los avatares que sufrió, tras su muerte el taller que regentaba.

\section{La herencia de Miguel Montañés}

Miguel Montañés era uno de esos artesanos de imprenta presentes en la Zaragoza de los primeros años del siglo dieciocho. Jiménez Catalán ya lo mencionó muy brevemente en su obra Ensayo de una tipografía zaragozana del siglo XVIII ${ }^{2}$ situando su vida profesional entre los años 1727-1730 como impresor del Hospital de Nuestra Señora de Gracia. Posteriormente, Roy Sinusía $^{3}$ volvió a señalar la cronología de este impresor pero sin llegar a matizar datos biográficos ni laborales de Montañés.

Nuevas investigaciones en el Archivo Diocesano y el Archivo del Colegio Notarial, ambos en Zaragoza, han aportado nuevos datos relevantes sobre la vida de este desconocido tipógrafo. El descubrimiento de la partida de su defunción en el libro parroquial de $\mathrm{La} \mathrm{Seo}^{4}$ proporciona su lugar de nacimiento, Lécera, así como la fecha de su defunción, el 15 de julio de 1730. Pero lo más importante radica en que en este escueto texto se indica el

\footnotetext{
1 Rosa María Blasco MartíneZ, Zaragoz̧a en el siglo XVIII, Zaragoza, Librería General, 1977.

2 Manuel JimÉNEZ CATALÁN, Ensayo de una tipografía zaragozana del siglo XVIII, Zaragoza, La Académica, 1929.

3 Manuel RoY SINUSíA, «Impresores y libreros dedicados a la estampa religiosa en Zaragoza durante los siglos XVIII y XIX», Memoria Ecclesiae XXXII. Imprenta y archivos de la Iglesia. Actas XXII. Congreso de la Asociación celebrado en Córdoba, Oviedo, Asociación de Archiveros de la Iglesia en España, 2009, pp. 157-214.
}

4 Archivo Diocesano de Zaragoza (ADZ). Libro sacramental de la parroquia de La Seo, 1729-1746, Tomo 7, p. 701.

Titivillus, ISSN 2387-0915, ISSN-e 2603-9966, 5 (2019), pp. 165-177 
nombre del notario Juan Antonio Loarre, encargado de redactar el testamento y las últimas voluntades del impresor Miguel Montañés.

Por suerte, a pesar de las vicisitudes que el Archivo del Colegio Notarial de Zaragoza ha sufrido a lo largo de su historia, dicho testamento ${ }^{5}$ se ha podido encontrar intacto. Este documento está fechado el 13 de julio, tan solo dos días antes de su muerte, pues es posible que Miguel Montañés ya se encontrara enfermo.

Gracias a este texto se sabe que Miguel Montañés estaba soltero pero que contaba con tres sobrinas, María, Teresa y Ana María a las que les legó pequeñas cantidades de dinero con la intención de ayudarlas en sus futuros matrimonios. Seguidamente, el testamento habla sobre las deudas que el Santo Hospital de Nuestra Señora de Gracia contrajo con él las cuales condona en un acto de generosidad.

Pero sin duda, el testamento de Montañés ofrece dos datos muy importantes para conocer la historia de la imprenta de Zaragoza. El primero es que el taller donde trabajaba había pertenecido anteriormente al impresor e infanzón Pascual Bueno (1678-1726) 6 quien se inició en el círculo de Juan Ibar y Juan Valero Berges.

A la muerte de Berges en 1668, Bueno se casó con su viuda, María Teresa Barón. Posteriormente se independizó en 1678 para regentar la Imprenta del Reino, la de la Universidad y la del Hospital de Nuestra Señora de Gracia. ${ }^{7}$

En la cédula testamentaria de Pascual Bueno ${ }^{8}$ hallada en el Archivo del Colegio Notarial se especifica, además de diversas donaciones a parientes y amigos, que se perdonen las deudas del Hospital de Nuestra Señora de Gracia y la donación de su imprenta a dicha institución, para que la vendiera o la regentara según su parecer.

El 10 de febrero de 1727 como se detalla en la escritura de compra-venta del taller de Pascual Bueno, ${ }^{9}$ los ejecutores de su testamento venden la imprenta a Miguel Montañés, Juan Malo y Diego Guindeo por 440 libras jaquesas.

El segundo dato que nos aporta el testamento de Miguel Montañés es el nombre de los herederos de su imprenta: Diego Guindeo y Juan Malo.

dexolos todos [los bienes] de gracia especial y de aquellos herederos mios universales, hago, instituio y nombro a Diego Guindeo y Juan Malo, tambien mancebos impresores compañeros mios residentes en esta ciudad,

5 Archivo Del Colegio Notarial de Zaragoza (ANZ). Testamento de Miguel Montañés, Protocolo de Juan Antonio Loarre, 1730, Signatura 5095, ff. 178v-179v.

6 Miguel Ángel Pallarés Jiménez y Esperanza Velasco de la PeÑa, La imprenta en Aragón, Zaragoza, Caja de Ahorros de la Inmaculada de Aragón, 2000, p. 66.

7 Ídem.

8 ANZ. Cédula de Pascual Bueno, Protocolo de Manuel de Leyza Erasso, 1726, signatura 4916, ff. $260 \mathrm{v}-267$.

9 ANZ. Venta de la imprenta, Protocolo de Juan Isidro Andrés, 1726, signatura 4864, f. 129. 
para que se los repartan y dividan a medias y por iguales partes y hagan y dispongan de ellos a su utilidad y beneficio como de bienes y cosa suia propia, adquirida con justo titulo como esta lo es

Hasta ahora esta información era desconocida debido a que los nombres de estos dos tipógrafos, Diego Guindeo y Juan Malo, no aparecen en ninguno de sus trabajos porque siempre firmaron como «herederos de Miguel Montañés».

Esta asociación laboral solamente permaneció activa durante un año a causa del prematuro fallecimiento de Guindeo. El hallazgo de su partida de defunción confirma la fecha de su muerte, el 19 de septiembre de 1731, su estado civil así como su edad: «Diego Guindeo, impresor, hombre mozo de edad de quarenta años poco mas o menos». ${ }^{10}$

En este texto también se nombra al notario Juan Antonio Loarre, encargado de notificar sus últimas voluntades. Dicho documento, en realidad, es un codicilo ${ }^{11}$ datado tres días antes de su muerte. Esta modificación se debió a que en su primer testamento ${ }^{12}$ dejó sus bienes a sus dos socios Miguel Montañés y Juan Malo, pero tras el fallecimiento del primero, Guindeo se vio en la obligación de cambiarlo para que Malo se convirtiera en el único heredero del taller.

\section{Las impresiones de Miguel Montañés y sus herederos}

Son pocas las obras impresas por Miguel Montañés que han llegado a nuestros días, posiblemente porque la franja cronológica en la que trabajó es muy escueta, concretamente desde 1727 a 1730.

Destacan las piezas de temática religiosa, como era habitual en la época, entre las que cabe mencionar algunos villancicos y oraciones panegíricas, aunque también elaboró obras de carácter jurídico.

Entre su repertorio, no se puede dejar de mencionar los textos que imprimió para el Santo Hospital de Nuestra Señora de Gracia (Fig. 1).

Tanto Pascual Bueno (Fig. 2), de quien heredó la imprenta Miguel Montañés, como sus sucesores (Fig. 3) Diego Guindeo y Juan Malo fueron impresores de dicho hospital lo que les supuso ostentar un cargo de gran reconocimiento y prestigio profesional, hecho que dejaron patente en sus publicaciones al incorporar la adición «impresor del Santo Hospital de Nuestra Señora de Gracia».

En cuanto a los impresos realizados por sus herederos siguen la misma línea que la empleada por Montañés puesto que al igual que este, apenas

\footnotetext{
10 ADZ. Libro sacramental de la parroquia de La Seo, 1729-1746, tomo 7, pp. 111-112.

11 ANZ. Codicilo de Diego Guindeo, Protocolo de Juan Antonio Loarre, 1731, signatura 5096 , ff. $430 \mathrm{v}-432 \mathrm{v}$.

12 ANZ. Testamento de Diego Guindeo, Protocolo de Juan Antonio Loarre, 1730, signatura 5095, ff. 169-169v.
}

Titivillus, ISSN 2387-0915, ISSN-e 2603-9966, 5 (2019), pp. 165-177 
trataron temas profanos. Solamente se conocen cuatro títulos debido a que, como se ha mencionado anteriormente, la asociación de Guindeo y Malo escasamente perduró un año.

\section{Conclusiones}

Las investigaciones realizadas a raíz del descubrimiento del testamento del impresor Miguel Montañés han permitido establecer diversos hechos hasta ahora desconocidos en relación con este taller.

Se ha podido averiguar la trayectoria de uno de los pocos talleres de imprenta establecidos en Zaragoza a principio del siglo XVIII, desde Pascual Bueno (1678-1726), pasando por Miguel Montañés (1727-1730), sus herederos Diego Guindeo y Juan Malo (1730-1731), para terminar con el único superviviente, Juan Malo, quien continuó con el taller hasta 1743 año de su fallecimiento. Todos ellos trabajaron para una de las más importantes instituciones de la época, el Hospital General de Nuestra Señora de Gracia.

Con estas aportaciones se ha conseguido ampliar la información de las figuras de estos cuatro impresores, aunque Pascual Bueno, Miguel Montañés y Juan Malo ya estaban documentados en los repertorios bibliográficos, no se había ahondado en sus perfiles profesionales y personales y en relación a Diego Guindeo, este había pasado completamente desapercibido pues en ninguna de sus impresiones firmó con su nombre completo.

En definitiva, todo esto supone un primer paso que nos acerca un poco más al conocimiento de la imprenta zaragozana de este siglo tan olvidada.

\section{Bibliografía de libros impresos por Miguel Montañés conocidos hasta}

\section{la fecha}

- MEMORIAL ajustado del pleyto de aprehension de la villa de Ayerbe y sus aldeas: pendiente por el oficio que govierna Don Pedro Sobron, En Zaragoza, por Miguel Montañes ..., 1727. CCPB000853375-X

- MONTANOS, Francisco de, Arte del canto llano con entonaciones comunes de coro, y altar, y otras cosas diversas ..., En Zaragoza, por Miguel Montañes, vendese en su casa, 1727. CCPB000400015-3

- VILLANCICOS que se han de cantar la tarde de el dia 15 de mayo en la... Iglesia Metropolitana Cesaraugustana en su... Templo de N[uestra] Señora del Pilar: en la fiesta que consagran los infantes a los siete convertidos por el Apostol Santiago..., En Zaragoza, por Miguel Montañes..., 1727. CCPB001208732-7

- $\quad$ MIRANDA ELIZALDE Y URSUA, Francisco Antonio de., Oracion sacra panegyrica que en la solemne fiesta, que en el dia 15 de marzo, celebrò la Santa Iglesia Cathedral de Tarazona, del glorioso San Raymundo de Serra... fundador del... Orden militar de Calatrava, con ocasion del nuevo rezado que ha concedido... Benedicto XIII 
para la dicha ciudad y toda su diocesis, En Zaragoza, por Miguel Montañes..., 1728. ССРВ000116780-4

- VILLANCICOS que se han de cantar la tarde del dia 24 de mayo en la... Iglesia Metropolitana Cesaraugustana en su... Templo de N [uestra] Señora del Pilar: en la fiesta que consagran los infantes a los siete convertidos por el Apostol Santiago, En Zaragoza, por Miguel Montañes..., 1728. CCРB001208733-5

- NABASA, Antonio de (O.F.M.), Candor divino reberverando en el espejo purissimo de Maria, formando la imagen de la divina bondad en el primer instante de su ser: oracion panegyrica de su Purissima Concepcion, en la solemnissima fiesta, que consagran ... Cabildo y ciudad de Jacca, en el Convento de San Francisco, en cumplimiento de el voto que el año del contagio hizo, En Zaragoza, por Miguel Montañes, impressor del Santo Hospital de N. Señora de Gracia, 1729. CCPB000401120-1

- AGUSTIN DE SAN JUAN BAUTISTA (Sch. P.), Artificiosae orationis sine rhetoricarum institutionum epitome..., Caesar-Augus.[tae], apud Michaelem Montañes..., 1730. CCPB000124845-6

- LAMANA, Diego, Sacro novendial de la Santa Familia y otros santos, con algunas devociones, y versos de mission, En Zaragoza, por Miguel Montañes ..., 1730. Aguilar Piñal. Bib. S.XVIII, V.5, n. 122

- TARragona (Archidiócesis). Arzobispo (1728-1753: Pedro Copóns Copóns), Memorial aiustado del pleyto de aprehension de los heredamientos, y quadras llamadas de Viberol, de la Madalana, y de Mallòs. A instancia del venerable Abad y Monges del Real Monasterio de N. Señora de Santa Maria de Poblet, del Orden Cisterciense. Pendiente por el oficio de D. Iuan Antonio Ramirez... en la lite pendente. Extrabido por Don Francisco Morana, su relator ..., En Zaragoza, por Miguel Montañes, en la calle de la cuchilleria, [ca. 1730]. CCPB000732102-3

- VILLANCICOS que se han de cantar la tarde del dia 15 de mayo de este año 1730 en la... Iglesia Metropolitana Cesar-Augustana en su... Templo de Nuestra Señora del Pilar: en la fiesta que consagran los infantes a los siete convertidos por el Apostol Santiago..., En Zaragoza, por Miguel Montañes..., [1730]. CCPB001208738-6

\section{Bibliografía de libros impresos por lo herederos de Miguel Montañés}

- EPINICIO sagrado con que la ... escuela aplaude a Maria ... en el Real Convento de San Francisco, En Zaragoza, por los Herederos de Miguel Montañes ..., 8 Diziembre 1730. CCPB000561094-X

- TReBiño, Francisco (S.I.), Sermon a la Purissima Concepcion de Maria Santissima: en la solemne festividad con que su Eximia Suarista Congregacion la celebrò en el Templo del Señor San Felipe Apostol, el dia 8 de diriembre de 1730, En Zaragoza, por los herederos de Miguel Montanés, [1730]. CCPB000267424-6 
- VILLANCICOS para la fiesta, que celebra, a Maria Santissima, en su Purissima Concepcion en el avgusto templo del señor San Felipe Apostol, la eximia svarista congregacion ..., el dia 8 de Diziembre de 1730, En Zaragoza, por los Herederos de Miguel Montañes..., [1730]. CСPB001011708-3

- ANGELICO trofeo que en festivo aparato de armoniosas consonancias celebra la angelica milicia en obsequio de la triunfante pureza de ... Santo Thomas de Aquino el domingo 18 de Febrero en el... Convento de San Ildefonso siendo prefecto ... Don Cenobio Alos ..., En Zaragoza, por los Herederos de Miguel Montanes [sic], 1731. CCPB000060811-4

\section{Transcripción del testamento del impresor Miguel Montañés ${ }^{13}$}

/178v/ Die duodecima mensis julii ano Domini millessimo septimgentesimo et trigesimo; Cesaragustei. Eodem die et loco. Que yo Miguel Montañes, mancebo impresor residente en esta ciudad de Zaragoza, estando enfermo de mi persona y por la misericordia de Dios Nuestro Señor en mi buen juicio y firme memoria y palabra manifiesta, rebocando todos y qualesquier testamentos, codecilos y ultimas disposiciones por mi, de mis bienes y hacienda, antes de aora hechos y ordenados aora de nuebo de mi buen grado y cierta ciencia. Hago y otorgo el presente mi testamento, ultimo voluntad y disposicion de todos mis bienes y hacienda, asi muebles como sitios, derechos, creditos, procesos, instancias y acciones donde quiere havidos y por haver en la forma y manera siguiente:

Primeramente, encomiendo mi alma a Dios Nuestro Señor, ecetera. Ittem, es mi voluntad que siempre y quando Dios Nuestro Señor dispusiere yo haya de morir, mi cuerpo sea enterrado con athaud y havito de mi serafico padre san Francisco de Assis en la iglesia de la parroquia donde acaeciere morir y que en ella me sean hechas mis difusion nobena y cabo de año, empleado en esto la cantidad de dinero que fuere necesaria de la que abaxo señalo. Ittem, es mi voluntad que de mis bienes y hacienda se tomen cien libras jaquesas y de ellas se satisfaga el gasto de mi entierro y el remanente que quedare de esta cantidad se emplee en hacerme decir y celebrar misas y sufragios por mi alma con la caridad de tres sueldos jaqueses por cada una de ellas celebradas en las partes y puestos que pareciere a mis executores, abaxo nombrados, a quienes encargo hagan celebrar todas las que se pudieren en la iglesia donde mi cuerpo sea enterrado. Ittem, remito y perdono al Santo Hospital Real y General de Nuestra Señora de Gracia de esta ciudad todo lo que este me estubiere deviendo de impresiones hasta el tiempo de mi fin y muerte de la parte que me pertenece /179r/ en la prensa donde trabaxo que fue del difunto Pasqual Bueno. Ittem, quiero se paguen todas mis deudas, ecetera. Ittem, dexo por parte y derecho de legitima herencia de todos mis bienes y

\footnotetext{
${ }^{13}$ Para la transcripción de los textos se ha optado por usar un estilo modernizado pero fiel al original. Se ha mantenido la ortografía y la gramática mientras que se han insertado signos de puntuación para facilitar su comprensión. Por este mismo motivo también se han añadido corchetes con los términos que se omitían en el texto, se han desarrollado las abreviaturas y por último, se han separado las palabras que estaban unidas entre sí. En el caso de la transcripción de varios folios, se ha indicado su foliación seguido de la letra " $\mathrm{r}$ " para el recto y "v" para el verso, todo ello entre barras inclinadas.
} 
hacienda asi muebles como sitios, derechos, creditos, procesos, instancias y acciones donde quiere havidos y por haver a qualquier parientes mios y personas otras que porte y derecho legitima herencia en dichos mis bienes y hacienda, pudieren pretender y alcanzar, cada cinco sueldos jaqueses por bienes muebles y otros tantos por bienes sitios. Ittem, dexo de gracia especial a Maria Montañes, mi sobrina dama moza residente en esta ciudad, hija legitima de Pasqual Montañes y de Maria Ana Muniesa, treinta libras jaquesas por una vez para que las cobre del Lizenciado don Blas Causada, presbitero escolar de la parroquia de la Santa Iglesia Metropolitana del Salbador de esta ciudad por otras tantas, este me esta deviendo dinero [que] le tengo prestado. Ittem, dexo de gracia especial a Theresa Pederre y Tafalla, mi sobrina dama moza residente en esta ciudad e hija legitima de los difuntos Antonio Pederre y de Rosa Tafalla, veinte y cinco libras jaquesas por una vez para aiuda a tomar estado. Ittem, dexo de gracia especial a Ana Maria Domingo, tambien mi sobrina hija de Pasqual Domingo y de Theresa Aznar, residente en esta ciudad, veinte libras jaquesas tambien por una vez y para quando llegue el caso de tomar estado. Y si alguna de las expresadas Theresa Pederre y Ana Maria Domingo, mis sobrinas, murieren sin tomar estado, es mi voluntad que la parte de la que asi faltare recaiga en los hermanos que tubiere en aquel o aquellos, que mis executores abaxo nombrados dispondran y tuvieren por comveniente. Ittem, satisfechas, pagadas y cumplidas todas las cosas por mi de parte de arriva dispuestas y ordenadas de todos los otros bienes mios, asi muebles $/ 179 \mathrm{v} /$ como sitios, ecetera, de los quales en este mi ultimo testamento no he hecho particular mencion. Los quales ecetera, dexolos todos de gracia especial y de aquellos herederos mios universales, hago, instituio y nombro a Diego Guindeo y Juan Malo, tambien mancebos impresores compañeros mios residentes en esta ciudad para que se los repartan y dividan a medias y por iguales partes y hagan y dispongan de ellos a su utilidad y beneficio como de bienes y cosa suia propia, adquirida con justo titulo como esta lo es. Ittem, finalmente dexo y nombro en executores del presente mi ultimo testamento y en exoneradores de mi alma y conciencia al Lizenciado don Blas Capdevilla, presbitero vicario de la Santa Iglesia Metropolitana del Salbador de esta ciudad, al dicho Lizenciado don Blas Causada presbitero escolar de la parroquia de la misma Santa Iglesia y a los dichos Diego Guindeo y Juan Malo, mancebos impresores residentes en esta ciudad, mis compañeros a los quales conformes o a la mayor parte de ellos, les doy todo el poder ecetera. Este es mi ultimo testamento, ecetera, fiat large. Testes Fabian Sebastian Ortiz mancebo y Joseph Mames Zapater escriviente y havitantes en la misma ciudad. Yo Miguel Montañes otorgo lo dicho. Yo Fabian Sebastian Ortiz soy testigo de lo dicho. Jospeh Mames Zapater soy testigo de lo dicho.

[/179r/ margen izquierdo: Ay apoca de esta escritura en el dia 13 de marzo de 1731. Otorgada por Juan Malo como heredero y executor del testador y obligacion de este para entregarselas, testificadas por mi. Loarre]

\section{Transcripción del testamento de Diego Guindeo}

/169r/ Eodem die et loco. Que yo Diego Guindeo, mancebo impresor residente en esta ciudad de Zaragoza, estando sano de mi persona y por la misericordia de Dios, Nuestro Señor, en mi buen juicio, firme memoria y palabra manifiesta, rebocando 
todos y qualesquiere testamentos, codicilos y ultimas disposiciones por mi de mis bienes y hacienda, antes de aora hechos y ordenados, aora de nuebo de mi buen grado, ecetera. Hago y otorgo el presente mi testamento, ultima voluntad y disposicion de todos mis bienes y hacienda, assi muebles como sitios, ecetera, en la forma y manera siguiente:

Primeramente, encomiendo mi alma a Dios, Nuestro Señor, ecetera. Ittem, es mi voluntad que siempre y cuando Dios Nuestro Señor dispusiere yo haia de morir, mi cuerpo sea sepultado con athaud y havito de mi serafico padre san Francisco de Assis en la iglesia parroquial donde acaeciere morir y que en ella me sean hechas mis defunsion y nobena y cabo de año, empleando en esta la cantidad de dinero que fuere necesario. Ittem, es mi voluntad que de mis bienes y hacienda se toman cien libras jaquesas y de ellas, se satisfaga el gasto de mi entierro y el remanente que quieran de esta cantidad se emple en hacerme decir y celebrar misas rezadas por mi alma con la caridad de tres sueldos jaqueses por cada una de ellas, celebraderas en las partes y puestos que pareciere a mis executores abaxo nombrados a quienes encargo hagan celebrar todas las que se pudieren en la iglesia donde mi cuerpo sea enterrado. Ittem, remito y perdono al Santo Hospital Real y General de Nuestra Señora de Gracia la tercera parte de todo lo que este estubiere deviendo de impresiones al tiempo de mi fin y muerte en la prensa donde trabaxo que fue del difunto Pasqual Bueno, cuia tercera parte es lo que a mi dicho testador me pertenece de lo que se estampa e imprime en ella. Ittem, dexo de gracia especial al Hospital de Niños y Niñas Guerfanos de esta ciudad ocho libras jaquesas de una vez. Ittem, quiero se paguen mis deudas, ecetera. Ittem, dexo por parte y derecho de legitima herencia de todos mis bienes y hacienda, assi muebles como sitios, ecetera, a qualesquiere parientes mios y personas otras que parte y derecho de legitima herencia en dichos mis bienes y hacienda pudieren pretender y alcanzar, cada cinco sueldos jaqueses por bienes muebles y otros tantos por bienes sitios. /169v/ Ittem, dexo de gracia especial a Maria Montañes, dama moza, hija de Pasqual Montañes y de Maria Ana Muniesa, residentes en esta ciudad diez libras jaquesas por una vez para siempre y quando tomare estado. Ittem, satisfechas, pagadas y cumplidas todas las cosas por mi de parte del arriva dispuestas y ordenadas de todos los otros bienes mios, assi muebles como sitios, ecetera, de los quales en este mi ultimo testamento no he hecho particular mencion, los quales ecetera, dexolos todos de gracia especial y de aquellos herederos mios universales, hago, instituio y nombro a Miguel Montañes y a Juan Malo, tambien mancebos impresores, compañeros mios, residentes en esta ciudad para que se los partan y dividan a medias y por iguales partes y hagan y dispongan de ellos a su virtud y beneficio como de bienes y cosa suia propia adquirida con justo titulo, como esta lo es. Ittem, finalmente dexo y nombro en executores del presente mi ultimo testamento y en el procuradores de mi alma y conciencia al lizenciado don Blas Capdevilla, presbitero vicario de la Santa Iglesia Metropolitana del Salbador de esta ciudad y a los dichos Miguel Montañes y Juan Malo, mancebos impresores, residentes todos en esta ciudad a los quales conformes o a la mayor parte de ellos, les doy todo el poder, ecetera. Este es mi ultimo testamento, ecetera. Fiat large. Testes Bernardo Barad y Marin y Manuel Urbieta escrivientes y havitantes en la misma ciudad de Zaragoza. Diego Guindeo otorgo lo dicho. Bernardo Barad y Martin soy testigo de lo dicho. Manuel Urbieta soy testigo de lo dicho.

Titivillus, ISSN 2387-0915, ISSN-e 2603-9966, 5 (2019), pp. 165-177 


\section{Transcripción del codicilo de Diego Guindeo}

/430v/ Die decima quarta mensis septembris anno Domini millesimo septimgentesim et trigesimo primo, Caesarangustei. Eodem die et loco, que yo don Diego Guindeo, mancebo impresor, residente en la presente ciudad de Zaragoza. Por quanto, y dicho otorgante tengo hecho y dispuesto mi testamento, que lo otorgue en esta ciudad el dia tres del mes de julio del año proxime pasado de mil setecientos y treinta y por el notario presente testificante testificado. Y por quanto, segun las disposiciones forales, observancias, ussos y costumbres de este reyno de Aragon, a cada testador es licito y permitido el hacer y otorgar uno o mas codicilos, añadiendo, corrigiendo, enmendando y quitando a su testamento. Por tanto, et alias, en aquella mejor forma ecetera, yo dicho Diego Guindeo, estando enfermo de mi persona, mas por la misericordia de Dios Nuestro Señor en mi buen juicio y firme memoria y palabra manifiesta, ussando y valiendome de dichas disposiciones forales, añadiendo, corrigiendo, declarando y enmendando el dicho mi testamento /431r/ de mi buen grado hago y otorgo el presente mi codecilo en la forma y manera siguiente:

Primeramente, en consideracion de que en dicho mi supra calendado testamento, dexaba de gracia especial a Maria Montañes, dama moza, hija de Pasqual Montañes y de Maria Ana Muniesa, residente en esta ciudad diez libras jaquesas por una vez, para siempre y quando tomare estado, por este mi codecilo, añadiendo a dicho legado, declaro es mi voluntad aumentarle otras diez libras jaquesas y que se le entreguen las veinte libras jaquesas siempre que llegue el citado caso de tomar aquella estado. Ittem, añadiendo por este mi codecilo a lo dispuesto en dicho mi testamento dexo de gracia especia a Lamberta Vella, mi criada, seis libras jaquesas por una vez. Ittem, por quanto por dicho mi testamento remitia y perdonaba al Santo Hospital Real y General de Nuestra Señora de Gracia de esta ciudad la tercera parte de todo lo que este estubiere deviendo de impresiones, al tiempo de mi fin y muerte, en la $/ 431 \mathrm{v} /$ prensa donde trabaxo que fue del difunto Pasqual Bueno por ser dicha tercera parte la que me pertenecia de lo que se estampaba e imprimia en ella. Y respecto de que al presente por haver muerto Miguel Montañes, mi compañero, de quien quede heredero con Juan Malo, me han pertenecido y pertenecen la mitad de los utiles de dicha prensa. Por lo que corrigiendo y enmendando el citado legado, por este mi codicilo declaro que remito y perdono a dicho Santo Hospital la mitad de todo lo que este estubiere deviendo de impresiones, al tiempo de mi fin y muerte, en la expresada prensa. Ittem por quanto por dicho mi testamento satisfecho lo por mi en el dispuesto del remanente de mis bienes, institui y nombre en herederos universales de todos ellos a Miguel Montañes y a Juan Malos, ambos mancebos impresores compañeros mios y residentes en esta ciudad, para que se los partiesen y dividiesen a medias y por iguales partes. Y respecto que como llebo dicho el dicho Miguel Montañes a muerto por lo que /432r/ declarando dicha clausula, de mi testamento por este mi codecilo declaro que satisfecho lo por mi dispuesto, asi en dicho testamento como en mi codecilo, del remanente de mis bienes instituio en heredero universal de todos ellos al dicho Juan Malo para que disponga de ellos a su beneficio como de cosa suia propia. Ittem, por quanto por el mismo, mi supra calendado testamento, nombre en executores de el al lizenciado don Blas Capdevilla presbitero vicario de la Santa Iglesia Metropolitana del Salbador de esta ciudad y al dicho Miguel Montañes. Y al respecto de que ambos han 
muerto, por este mi codecilo, aumentando dicha clausula declaro nombro en executores de aquel y de este mi codecilo, al doctor don Juan Francisco Guillen, presbitero vicario actual de dicha Santa Iglesia, al qual con el dicho Juan Malo, nombrado tambien por mi executor en dicho testamento, les doy todo el poder, ecetera. Ittem, finalmente quiero que todas las demas cosas contenidas en dicho mi supra calendado testamento queden en su justa eficacia y valor, como antes del otorgamiento de este mi codecilo lo estaban, en aquel, sin que se entienda haver mudarse alguna en ellas, mas que lo por mi dispuesto de parte de arriva. Este es mi ultimo codecilo, ecetera. Fiat large. Testes Juan Joseph Arrieta Texada, mancebo, y Manuel Urbieta, escrivientes havitantes en la misma ciudad de Zaragoza. Diego Guindeo otorgo lo dicho. Juan Joseph Arrieta Texada soi testigo de lo dicho. Manuel Urbieta soy testigo de lo dicho.

\section{Figuras}

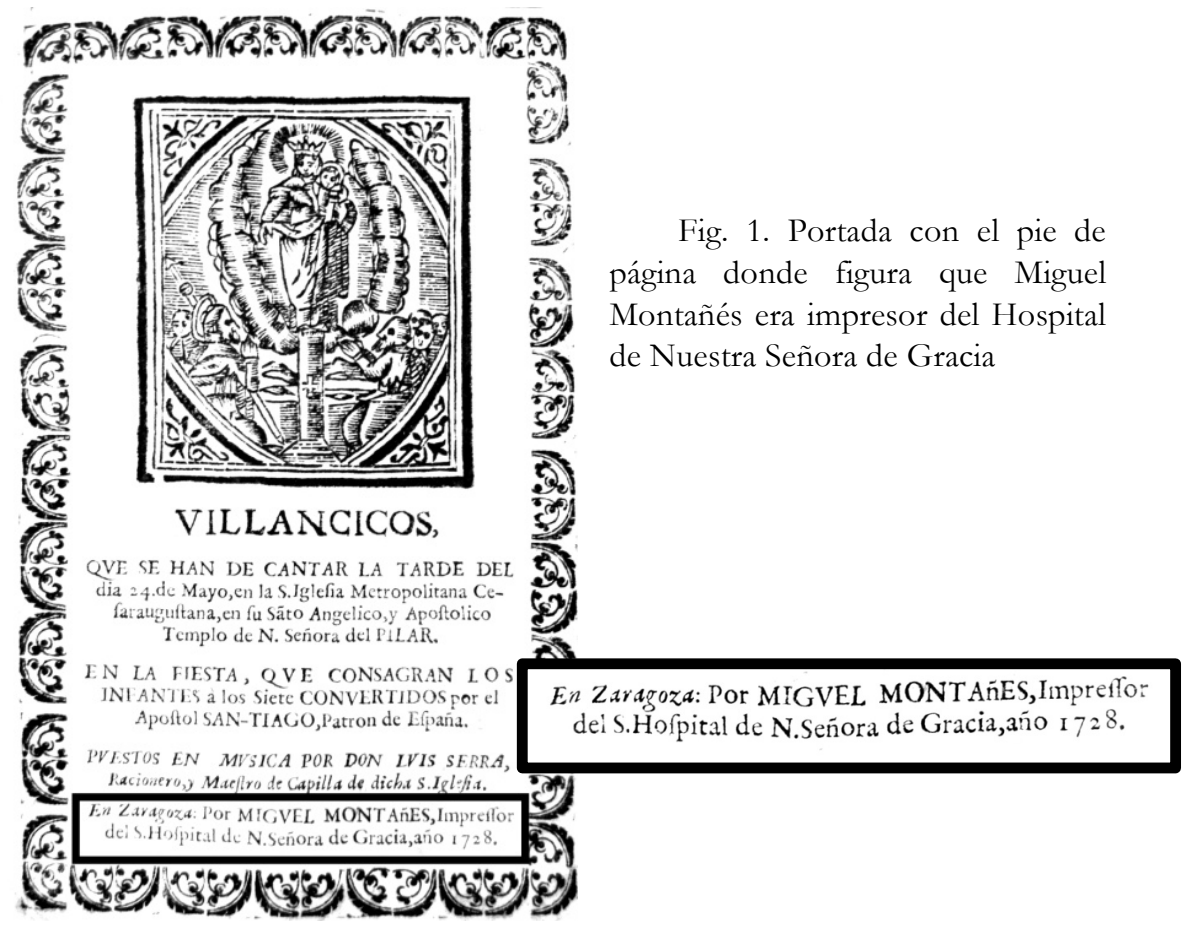



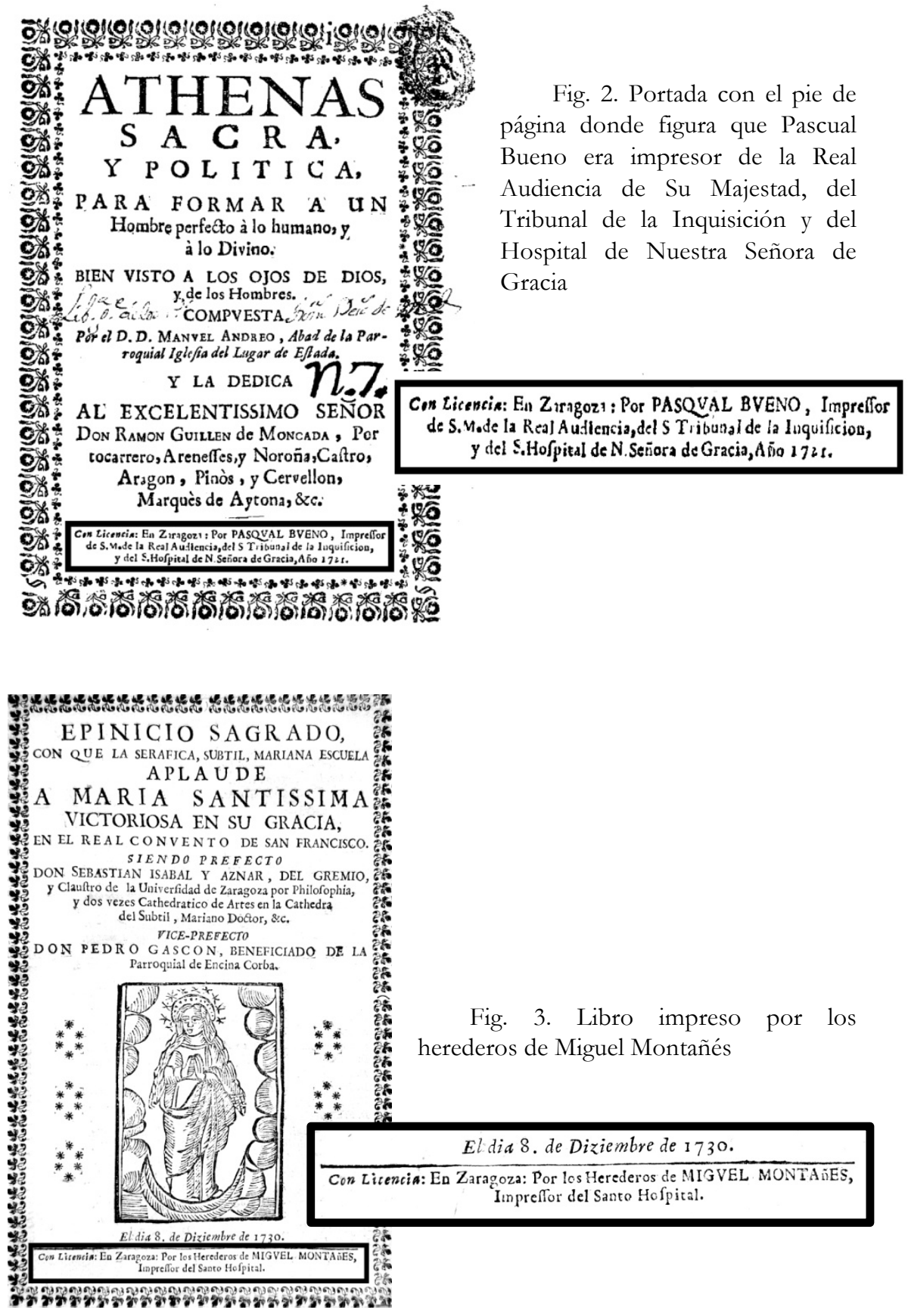

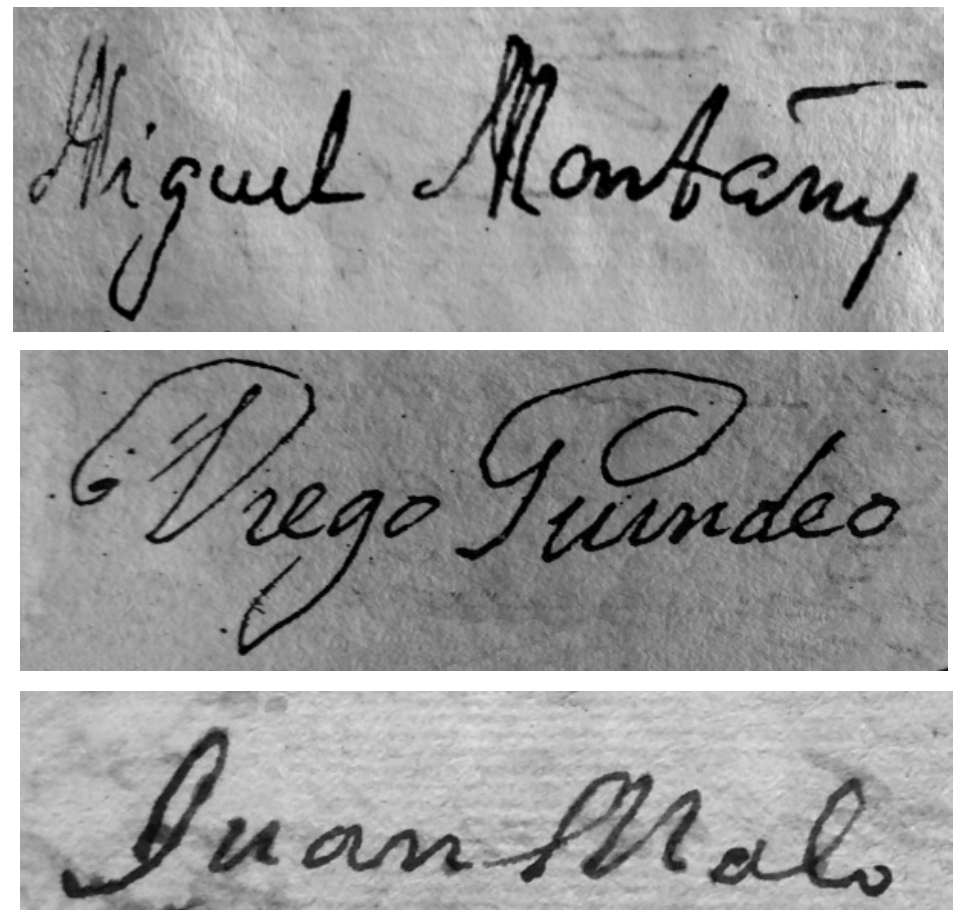

Fig. 4. Firmas de Miguel Montañés, Diego Guindeo ${ }^{14}$ y Juan Malo ${ }^{15}$.

14 Firmas extraídas de: Ibídem. ANZ. Testamento de Miguel Montañés y de Diego Guindeo.

15 Firma extraída de: Ibídem. ANZ. Venta de la imprenta de Pascual Bueno.

Titivillus, ISSN 2387-0915, ISSN-e 2603-9966, 5 (2019), pp. 165-177 